\title{
Intra-operative high intensity focused ultrasound in patients with colorectal liver metastases: results of a phase I-II study in 21 patients
}

\author{
David Melodelima1*, Aurelien Dupre², Chen Yao², Jeremy Vincenot ${ }^{1}$, Jean-Yves Chapelon', Michel Rivoire ${ }^{2}$ \\ From Current and Future Applications of Focused Ultrasound 2014. 4th International Symposium \\ Washington, D.C, USA. 12-16 October 2014
}

\section{Background/introduction}

Managing colorectal liver metastases (CLM) is a major clinical challenge, and surgery remains the only potentially curative treatment. Five-year survival rates of up to $51 \%$ have been recently reported. However, only $10-20 \%$ of patients are eligible for surgery, which is often precluded by the number, size and/or location of metastases, or because the necessary resection will leave insufficient volume of functional liver. A toroidal transducer for HIFU ablation has been developed and tested in vivo enabling destruction of large liver volumes. Preliminary in vitro and preclinical work demonstrated the potential, feasibility and safety of such HIFU ablations. These preclinical studies are now translated into clinical practice through controlled trials, and the aim of this study was to assess the feasibility and safety of HIFU ablation in patients undergoing hepatectomy for CLM, as well to collect preliminary efficacy and accuracy data.

\section{Methods}

The transducer has a toroidal shape $70 \mathrm{~mm}$ in diameter and is divided into 32 ultrasound emitters of $0.13 \mathrm{~cm} 2$ operating at $3 \mathrm{MHz}$. The radius of curvature is $70 \mathrm{~mm}$. A 7.5 $\mathrm{MHz}$ ultrasound imaging probe was placed in the centre of the device and was used to guide the treatment. The imaging plane was aligned with the HIFU focal zone. The clinical protocol was reviewed and validated by a national ethics committee according to European directives. Since this study was the first use in man of intra-operative hepatic HIFU, ablations were made only in the part of the liver scheduled for resection. This allowed real-time evaluation of HIFU ablation while protecting participating patients from any adverse effects related to this new technique. Only areas included within the planned resection were treated with HIFU. Six patients were included in the Phase I. Two single thermal ablations were created in each patient. Thirteen patients were included in Phase IIa and two HIFU ablations were to be placed precisely in a target previously identified in ultrasound images (step 1) and then at distance (step 2) from a target. Two patients were included in Phase IIb. HIFU ablations were created to ablate metastases ( $20 \mathrm{~mm}$ maximal diameter) with safety margins in all directions.

\section{Results and conclusions}

In agreement with preclinical studies, the demarcation between ablated and non-ablated tissue was clearly apparent in ultrasound images and histology.

The dimensions measured on ultrasound imaging were correlated $(\mathrm{r}=0.88, \mathrm{p}<0.0001)$ with dimensions measured during histological analysis. All HIFU ablations were obtained in 40 seconds. The average dimensions obtained from each HIFU ablation were a diameter of $21.0 \pm 3.9$ $\mathrm{mm}$ and a depth of $27.5 \pm 6.0 \mathrm{~mm}$. The phase IIa study showed both that the area of ablation could be precisely targeted on a previously implanted metallic mark and that ablations could be created deliberately to avoid such a mark. Ablations were achieved with a precision of 1-2 $\mathrm{mm}$. In Phase IIb, one metastasis of $10 \mathrm{~mm}$ in diameter was ablated in 40 seconds with safety margins. Using electronic focusing a second metastasis was ablated with safety margins in 130 seconds. The dimensions of the HIFU ablation were a diameter of $48 \mathrm{~mm}$ and a long axis of $51 \mathrm{~mm}$. HIFU was feasible, safe and effective in ablating large areas of liver scheduled for resection.

${ }^{1}$ Inserm, Lyon, France

Full list of author information is available at the end of the article 


\section{Acknowledgements (Funding)}

This work was supported by funding from the Cancéropôle Lyon Auvergne Rhône Alpes and the French NCl (under PHRC grant 12007 and Lyric grant INCa-DGOS-4664).

\section{Authors' details}

${ }^{1}$ Inserm, Lyon, France. ${ }^{2}$ Centre Leon Berard, Lyon, France.

Published: 30 June 2015

doi:10.1186/2050-5736-3-S1-082

Cite this article as: Melodelima et al.: Intra-operative high intensity focused ultrasound in patients with colorectal liver metastases: results of a phase I-II study in 21 patients. Journal of Therapeutic Ultrasound 2015 3(Suppl 1):082.

Submit your next manuscript to BioMed Central and take full advantage of:

- Convenient online submission

- Thorough peer review

- No space constraints or color figure charges

- Immediate publication on acceptance

- Inclusion in PubMed, CAS, Scopus and Google Scholar

- Research which is freely available for redistribution

Submit your manuscript at www.biomedcentral.com/submit 